\title{
Poor self-rated health predicts mortality in patients with stable chronic heart failure
}

European Journal of Cardiovascular Nursing 2016, Vol. 15(7) 504-512

(C) The European Society of Cardiology 2015 Reprints and permissions: sagepub.co.uk/journalsPermissions.nav DOI: $10.1177 / 1474515$ II56/5254 cnu.sagepub.com

(S)AGE

\author{
Simone Inkrot', Mitja Lainscak ${ }^{2,3}$, Frank Edelmann 1,4,5, \\ Goran Loncar,7, Ivan Stankovic ${ }^{8}$, Vera Celic ${ }^{7,9}$, Svetlana Apostolovic ${ }^{10}$, \\ Elvis Tahirovic', Tobias Trippel', Christoph Herrmann-Lingen ${ }^{5,1}$, \\ Götz Gelbrich'2,13 and Hans-Dirk Düngen'
}

\begin{abstract}
Aims: In heart failure, a holistic approach incorporating the patient's perspective is vital for prognosis and treatment. Self-rated health has strong associations with adverse events and short-term mortality risk, but long-term data are limited. We investigated the predictive value of two consecutive self-rated health assessments with regard to long-term mortality in a large, well characterised sample of elderly patients with stable chronic heart failure.

Methods and results: We measured self-rated health by asking 'In general, would you say your health is: I, excellent; 2, very good; 3, good; 4, fair; 5, poor?' twice: at baseline and the end of a I2-week beta-blocker up-titration period in the CIBIS-ELD trial. Mortality was assessed in an observational follow-up after 2-4 years. A total of 720 patients (mean left ventricular ejection fraction $45 \pm 12 \%$, mean age $73 \pm 5$ years, $36 \%$ women) rated their health at both time points. During long-term follow-up, 144 patients died (all-cause mortality 20\%). Fair/poor self-rated health in at least one of the two reports was associated with increased mortality (hazard ratio 1.42 per level; 95\% confidence interval I.I6-I.75; $P<0.00 \mathrm{I})$. It remained independently significant in multiple Cox regression analysis, adjusted for $\mathrm{N}$-terminal pro B-type natriuretic peptide (NTproBNP), heart rate and other risk prediction covariates. Self-rated health by one level worse was as predictive for mortality as a I.9-fold increase in NTproBNP.

Conclusion: Poor self-rated health predicts mortality in our long-term follow-up of patients with stable chronic heart failure, even after adjustment for established risk predictors. We encourage clinicians to capture patient-reported selfrated health routinely as an easy to assess, clinically meaningful measure and pay extra attention when self-rated health is poor.
\end{abstract}

\section{Keywords}

Heart failure, self-rated health, mortality, risk prediction, elderly

Date received 22 June 20I5; revised 9 October 20I5; accepted 13 October 2015

\footnotetext{
'Department of Internal Medicine - Cardiology,

Charité-Universitätsmedizin Berlin, Germany

2University Department of Cardiology, General Hospital Celje, Slovenia

${ }^{3}$ Faculty of Medicine, University of Ljubljana, Slovenia

${ }^{4}$ Department of Cardiology and Pneumology, University of Göttingen, Germany

${ }^{5}$ German Center for Cardiovascular Research, Germany

${ }^{6}$ Department of Cardiology, Clinical Hospital Zvezdara, Serbia

${ }^{7}$ School of Medicine, University of Belgrade, Serbia

${ }^{8}$ Department of Cardiology, Clinical Hospital Centre Zemun, Serbia

${ }^{9}$ Cardiology Department, University Clinical Hospital Center "Dr

Dragisa Misovic-Dedinje”, Belgrade, Serbia
}

\footnotetext{
${ }^{10}$ Faculty of Medicine, University of Nis, Serbia

"Department of Psychosomatic Medicine and Psychotherapy, University of Göttingen Medical Center, Germany

${ }^{12}$ Institute of Clinical Epidemiology and Biometry, University of Würzburg, Germany

${ }^{13}$ Clinical Trial Center, University Hospital Würzburg, Germany

The final two authors share senior authorship.

Corresponding author:

Simone Inkrot, Department of Internal Medicine - Cardiology, Charité Universitätsmedizin Berlin, Campus Virchow-Klinikum, Augustenburger Platz I, I 3353 Berlin, Germany.

Email: simone.inkrot@charite.de
} 


\section{Introduction}

Heart failure is a clinical syndrome caused by functional or structural abnormalities of the heart, resulting in its inability to meet fully the body's oxygen demands. ${ }^{1}$ Approximately $10 \%$ of adults 70 years of age or older experience heart failure and $2 \%$ of the adult population in developed countries is affected. ${ }^{1}$ The spectrum of the effects of heart failure is vast, but it is undeniably a challenging syndrome - costly for health systems and debilitating for the person affected. Decompensation is common in heart failure and is potentially life threatening, and it is vital to identify patients at high risk to be able to target treatment individually. ${ }^{2}$ In a holistic approach to treatment, the patient's experience can be assessed by patient-reported outcomes. ${ }^{3}$ Self-rated health, sometimes referred to as 'overall perceived health', is the term given to a person's own perspective of their health status. It can be measured simply by asking: 'Would you say in general your health is: excellent (1), very good (2), good (3), fair (4), or poor (5)?'

It is known that a person's own perspective of their health is vital to outcome and self-rated health has strong associations with mortality risk in healthy populations. ${ }^{4}$ Persons with good self-rated health are more likely to engage in physical activity and adhere to prescribed treatment. ${ }^{5}$ In patients with other chronic diseases such as diabetes mellitus, self-rated health independently predicts functional decline, health care utilisation and mortality. ${ }^{6}$ Lack of subjective improvement of one's health after a myocardial infarction increases the risk of recurring ischaemic events, indicating a benefit of consecutive assessment of self-rated health. ${ }^{7}$

Self-rated health in patients with heart failure is worse than in the general population ${ }^{4,8}$ and patients with other chronic health conditions such as chronic obstructive pulmonary disease, ${ }^{9}$ long-term dialysis treatment ${ }^{10}$ or chronic pain. ${ }^{11}$ It is an independent predictor of adverse events during beta-blocker up-titration. ${ }^{12}$

The importance of patient-reported outcomes in chronic cardiovascular disease has recently been highlighted by Anker et al., ${ }^{3}$ but available information on self-rated health and mortality in heart failure is still limited. Two post-hoc analyses of data gathered in randomised trials highlighted a utility of self-rated health in predicting mortality, but the mean age of both samples was 10 years younger than the mean age of chronic heart failure patients in the community. ${ }^{13,14}$ Three prospective studies demonstrated that a single self-rated health assessment predicts mortality in older patients with suspected ${ }^{15}$ and confirmed ${ }^{16,17}$ heart failure. To the best of our knowledge, there is no information on consecutive assessments of self-rated health in this population.

The authors of a systematic review and meta-analysis of prospective studies investigating the predictive value of patient-reported symptoms, functioning and health-related quality of life agreed that although results remain mixed, self-reported health status is an independent risk indicator for prognosis in heart failure. ${ }^{18}$ However, due to the heterogenic nature of self-report assessment instruments used within the studies, no guidance can be given as to which instrument may be most useful. Considering conceptual differences between quality of life, self-rated health and perceptions of symptoms and limitations on daily life, it appears difficult to analyse and interpret the results together. We all ask our patients 'how are you', but standardised self-rated health assessment has not yet entered routine clinical practice. This has practical as well as methodological reasons, including challenges surrounding the clinical interpretation of scores. ${ }^{18}$ Self-rated health, as a simple, one-item measure is easy to administer and has limited variability of score interpretation.

The aim of this analysis was to investigate the predictive value of two consecutive, standardised self-rated health assessments with regard to mortality in a large, well characterised sample of elderly patients with stable chronic heart failure on maximally tolerated beta-blocker treatment.

\section{Methods}

\section{Design, setting and participants}

In this prospective study, we examined self-rated health and mortality in patients who had participated in the investigator-initiated Cardiac Insufficiency Bisoprolol Study in Elderly (CIBIS-ELD) between 2005 and 2008. The CIBISELD protocol and main results have been published previously. ${ }^{19,20}$ In brief, CIBIS-ELD was a double-blind, randomised controlled trial conducted in 41 European centres (Germany, Montenegro, Serbia and Slovenia). We enrolled patients who experienced symptomatic chronic heart failure with reduced ejection fraction (HFrEF) or normal ejection fraction. Patients were randomly assigned to receive either bisoprolol or carvedilol, and these were up-titrated to the highest tolerated dose over a period of 12 weeks. The primary aim of CIBIS-ELD was to compare both agents with regards to the tolerability of target doses.

Of 883 CIBIS-ELD patients, 720 patients who had provided information on self-rated health before and after beta-blocker up-titration could be assessed for all-cause mortality in an observational follow-up after $2-4$ years, between 2010 and 2012 (Figure 1). Due to a very low recruitment rate at the beginning of the study, there were only a few patients with a follow-up of more than 4 years. Therefore, we decided to truncate follow-up information at 4 years in all analyses.

The protocol was approved by all national and local ethics committees. Patients provided written informed consent and the study conforms to the principles outlined in the 1975 Declaration of Helsinki. 


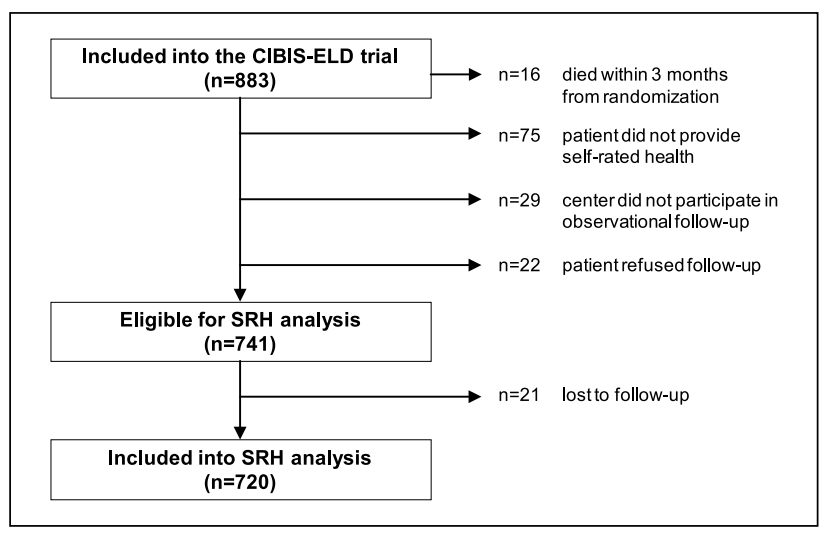

Figure I. Patient selection flow chart.

\section{Data collection and definitions}

Data on patient demographic characteristics, medical history and medication were retrieved from medical records and patients. Electrocardiogram and echocardiography were retrieved from medical records (if less than 3 months old) or performed on the day of the clinic visit for the study. Medical and nursing assessment included standardised physical examination, New York Heart Association (NYHA) functional class, vital status, body weight, height and sociodemographic information. Heart rate was obtained by clinical examination or from electrocardiogram if performed at the clinic visit. Body mass index (BMI) was calculated from body weight and height $\left(\mathrm{kg} / \mathrm{m}^{2}\right) .^{21}$ Laboratory parameters were obtained on the day of the clinic visit. This included measurement of $\mathrm{N}$-terminal pro B-type natriuretic peptide (NTproBNP) as a clinically and prognostically significant marker of heart failure severity. ${ }^{1}$ Anaemia was defined according to the World Health Organization threshold values for haemoglobin: $<120 \mathrm{~g} / 1$ for women and $<130 \mathrm{~g} / 1$ for men. ${ }^{22}$ Exercise capacity was measured with a 6-minute walk test, which was performed according to the guidelines issued by the American Thoracic Society. ${ }^{23}$

Self-reported quality of life, social functioning and physical function was measured using the Medical Outcomes Study short form-36 questionnaire (SF-36), with higher scores indicating better value on a scale of 0 to 100. ${ }^{24}$ Depression was measured with the self-report patient health questionnaire (PHQ-9), with scores ranging from 0 to $27 .{ }^{25}$ Higher scores indicate a greater severity of depressive symptoms.

Patients were handed all self-report questionnaires and instructed to complete the answers independently. To minimise social desirability bias and ensure anonymity, patients were offered to take questionnaires home and return them by the stamped envelope provided. A research nurse was available to assist patients if requested.

Vital status (alive or dead) at follow-up was obtained from patients, their relatives, general practitioners, review of medical records or state registries. In some cases, no information could be obtained if no registry was held by the state and all other methods of data collection failed.

\section{Self-rated health}

We measured self-rated health by asking 'In general, would you say your health is...?', using a five-point Likert scale with lower numbers indicating better self-rated health: 1, excellent; 2 , very good; 3 , good; 4 , fair; 5 , poor. This patientreported single-item overall health assessment is part of the SF-36. Validity and reliability have been established. ${ }^{26} \mathrm{We}$ measured self-rated health at baseline and at the end of the 12 -week titration period. Since there may be several hypotheses regarding which combination of two serial measurements of self-rated health is most predictive, we explored the relationship of the last observation, the average, the worst and the best of both with mortality. 'Worst of both' was the one with the strongest relationship to mortality. Therefore, detailed results are reported for that one.

\section{Statistics}

Baseline data are presented as or mean \pm standard deviation for quantitative variables (median and quartiles for NTproBNP) or frequencies and percentages for categories. We used Kendall's correlation coefficient to examine whether worse self-rated health was associated with unfavourable baseline characteristics. The primary endpoint was all-cause mortality. Survival is presented by KaplanMeier curves. To quantify the relationship between selfrated health and the primary endpoint and to adjust for covariables, we used Cox proportional hazard regression.

Statistical calculations were performed using SPSS for Windows version 20.0 (IBM Inc.). All statistical tests were two-sided with $P$ values less than 0.05 considered significant.

\section{Results}

\section{Subjects}

Patient characteristics at the end of up-titration are displayed in Table 1. The sample consisted of a typical chronic stable heart failure population with $\mathrm{HFrEF}$ or heart failure with preserved ejection fraction (HFpEF). Mean left ventricular ejection fraction was $45 \pm 12 \%$, mean age was $73 \pm 5$ years and $36 \%$ were women. Patients were on maximally tolerated pharmaceutical treatment for heart failure. During the $2-4$ years observation period, 144 patients died (20\%).

\section{Self-rated health}

Just over half of our study participants ( $\mathrm{n}=367,51 \%)$ rated their health as fair or poor (Table 1). Lower self-rated health was associated with living alone, being female, 
Table I. Baseline characteristics (at the end of beta-blocker up-titration).

\begin{tabular}{|c|c|c|c|c|c|c|}
\hline \multirow[t]{3}{*}{ Variable } & \multirow{3}{*}{$\begin{array}{l}\text { All patients } \\
(n=720)\end{array}$} & \multicolumn{4}{|c|}{$\begin{array}{l}\text { Subgroup by self-rated health (worst of two } \\
\text { observations) }\end{array}$} & \multirow[t]{3}{*}{$P$ value } \\
\hline & & \multirow{2}{*}{$\begin{array}{l}\text { Excellent or } \\
\text { very good } \\
(n=45)\end{array}$} & \multirow{2}{*}{$\begin{array}{l}\text { Good } \\
(n=308)\end{array}$} & \multirow{2}{*}{$\begin{array}{l}\text { Fair } \\
(n=277)\end{array}$} & \multirow{2}{*}{$\begin{array}{l}\text { Poor } \\
(n=90)\end{array}$} & \\
\hline & & & & & & \\
\hline \multicolumn{7}{|l|}{ Sociodemographics } \\
\hline Age (years), mean $\pm S D$ & $72.9 \pm 5.4$ & $71.9 \pm 5.0$ & $72.6 \pm 5.4$ & $73.4 \pm 5.3$ & $73.4 \pm 5.9$ & 0.080 \\
\hline Female sex, n (\%) & $26 \mid(36)$ & $13(29)$ & $88(29)$ & $122(44)$ & $38(42)$ & $<0.001$ \\
\hline Current smoker, n (\%) & $61(9)$ & $2(4)$ & $26(8)$ & $26(9)$ & $7(8)$ & 0.576 \\
\hline Living alone, n (\%) & $260(36)$ & $12(27)$ & $98(32)$ & $108(39)$ & $42(47)$ & 0.002 \\
\hline High educational level, n (\%) & $337(47)$ & $27(60)$ & $153(50)$ & $129(47)$ & $28(31)$ & 0.002 \\
\hline \multicolumn{7}{|l|}{ Clinical measurements } \\
\hline Body mass index $\left(\mathrm{kg} / \mathrm{m}^{2}\right)$, mean $\pm \mathrm{SD}$ & $27.8 \pm 4.7$ & $27.8 \pm 4.3$ & $27.6 \pm 4.3$ & $28.4 \pm 5.0$ & $27.0 \pm 4.9$ & 0.855 \\
\hline Systolic blood pressure $(\mathrm{mmHg})$, mean $\pm \mathrm{SD}$ & $129 \pm 19$ & $129 \pm 19$ & $128 \pm 17$ & $129 \pm 20$ & $128 \pm 19$ & 0.787 \\
\hline $\begin{array}{l}\text { Diastolic blood pressure }(\mathrm{mmHg}) \\
\text { mean } \pm \mathrm{SD}\end{array}$ & $76 \pm 10$ & $77 \pm 9$ & $76 \pm 10$ & $76 \pm 10$ & $75 \pm 11$ & 0.368 \\
\hline Heart rate on ECG (bpm), mean \pm SD & $67 \pm 13$ & $65 \pm 10$ & $66 \pm 12$ & $67 \pm 13$ & $69 \pm 15$ & 0.158 \\
\hline $\begin{array}{l}\text { Left ventricular ejection fraction (\%), } \\
\text { mean } \pm S D\end{array}$ & $45 \pm 12$ & $42 \pm 9$ & $44 \pm 11$ & $46 \pm 14$ & $43 \pm 13$ & 0.084 \\
\hline Six-minute walk distance $(m)$, mean $\pm S D$ & $339 \pm 104$ & $349 \pm 97$ & $355 \pm 97$ & $332 \pm 108$ & $301 \pm 112$ & $<0.001$ \\
\hline NYHA class, n (\%) & & & & & & $<0.001$ \\
\hline $\mathrm{I}$ & $109(15)$ & $5(\mathrm{II})$ & $63(20)$ & $32(12)$ & $9(10)$ & \\
\hline II & $504(70)$ & $36(80)$ & $218(71)$ & $194(70)$ & $56(62)$ & \\
\hline III & $100(14)$ & $4(9)$ & $24(8)$ & $47(17)$ & $25(28)$ & \\
\hline IV & $7(1)$ & $0(0)$ & $3(1)$ & $4(\mathrm{I})$ & $0(0)$ & \\
\hline $\mathrm{FEV}_{\mathrm{I}}(\mathrm{ml})$, mean $\pm \mathrm{SD}$ & $2184 \pm 658$ & $245 I \pm 620$ & $2291 \pm 666$ & $2080 \pm 608$ & $200 I \pm 698$ & $<0.001$ \\
\hline Peripheral oedema, n (\%) & $80(11)$ & $3(7)$ & $24(8)$ & $40(14)$ & $13(14)$ & 0.005 \\
\hline $\begin{array}{l}\text { Hospitalisation for heart failure in the past } \\
\text { year, } n(\%)\end{array}$ & $263(37)$ & II (24) & $104(34)$ & $109(39)$ & $39(43)$ & 0.012 \\
\hline \multicolumn{7}{|l|}{ Comorbidities } \\
\hline Atrial fibrillation, n (\%) & $|4|(20)$ & $6(13)$ & $44(14)$ & $62(22)$ & $29(32)$ & $<0.001$ \\
\hline Coronary heart disease, $\mathrm{n}(\%)$ & $425(59)$ & $30(67)$ & $197(64)$ & $149(54)$ & $49(54)$ & 0.008 \\
\hline Diabetes mellitus, n (\%) & $184(26)$ & $15(33)$ & $74(24)$ & $69(25)$ & $26(29)$ & 0.896 \\
\hline $\begin{array}{l}\text { Chronic obstructive pulmonary } \\
\text { disease, } \mathrm{n}(\%)\end{array}$ & $53(7)$ & $2(4)$ & $17(6)$ & $25(9)$ & $9(10)$ & 0.045 \\
\hline History of depression, $\mathrm{n}(\%)$ & $55(8)$ & $2(4)$ & $10(3)$ & $3 I(I I)$ & $12(13)$ & $<0.001$ \\
\hline \multicolumn{7}{|l|}{ Laboratory } \\
\hline Serum sodium $(\mathrm{mmol} / \mathrm{l})$, mean $\pm \mathrm{SD}$ & $|4| \pm 4$ & $|4| \pm 3$ & $|4| \pm 4$ & $|4| \pm 4$ & $|4| \pm 4$ & 0.318 \\
\hline Serum potassium $(\mathrm{mmol} / \mathrm{l})$, mean $\pm S D$ & $4.4 \pm 0.5$ & $4.5 \pm 0.4$ & $4.4 \pm 0.5$ & $4.4 \pm 0.5$ & $4.5 \pm 0.6$ & 0.650 \\
\hline Haemoglobin $(g / d l)$, mean $\pm S D$ & $13.5 \pm 1.6$ & $13.7 \pm 1.4$ & $13.7 \pm 1.6$ & $13.4 \pm 1.6$ & $13.2 \pm 1.5$ & 0.002 \\
\hline eGFR $\left(\mathrm{ml} / \mathrm{min} / \mathrm{I} .73 \mathrm{~m}^{2} \mathrm{BSA}\right)$, mean $\pm \mathrm{SD}$ & $63 \pm 18$ & $59 \pm 16$ & $65 \pm 17$ & $63 \pm 19$ & $61 \pm 19$ & 0.267 \\
\hline Uric acid $(\mathrm{mg} / \mathrm{dl})$, mean $\pm \mathrm{SD}$ & $6.0 \pm 1.8$ & $5.6 \pm 1.7$ & $5.9 \pm 1.7$ & $6.1 \pm 1.9$ & $6.4 \pm 2.0$ & 0.027 \\
\hline Total cholesterol (mg/dl), mean \pm SD & $203 \pm 48$ & $209 \pm 51$ & $203 \pm 45$ & $202 \pm 49$ & $200 \pm 54$ & 0.341 \\
\hline $\begin{array}{l}\text { NTproBNP (ng/l), median (interquartile } \\
\text { range) }\end{array}$ & $\begin{array}{l}663 \\
(282-1477)\end{array}$ & $\begin{array}{l}757 \\
(280-1160)\end{array}$ & $\begin{array}{l}519 \\
(227-1199)\end{array}$ & $\begin{array}{l}719 \\
(361-1748)\end{array}$ & $\begin{array}{l}968 \\
(384-2168)\end{array}$ & $<0.001$ \\
\hline \multicolumn{7}{|l|}{ Medications } \\
\hline ACE inhibitor and/or ARB, $n(\%)$ & $6 \mid 4(85)$ & $40(89)$ & $260(84)$ & $239(86)$ & $75(83)$ & 0.872 \\
\hline Beta-blocker, n (\%) & $706(98)$ & $44(98)$ & $299(97)$ & $275(99)$ & $88(98)$ & 0.236 \\
\hline Diuretic, n (\%) & $528(73)$ & $32(7 I)$ & $219(7 I)$ & $205(74)$ & $72(80)$ & 0.113 \\
\hline Aldosterone receptor antagonist, n (\%) & $233(32)$ & $14(31)$ & $95(31)$ & $83(30)$ & $4 I(46)$ & 0.126 \\
\hline Cardiac glycoside, n (\%) & $104(14)$ & $4(9)$ & $4 \mid(13)$ & $38(14)$ & $21(23)$ & 0.051 \\
\hline Statin, n (\%) & $284(39)$ & $23(5 \mathrm{I})$ & $|3|(43)$ & $108(39)$ & $22(24)$ & 0.002 \\
\hline Anti-platelet therapy, n (\%) & $487(68)$ & $33(73)$ & $221(72)$ & $180(65)$ & $53(59)$ & 0.009 \\
\hline Anticoagulant, n (\%) & $179(25)$ & $13(29)$ & $70(23)$ & $68(25)$ & $28(31)$ & 0.364 \\
\hline
\end{tabular}


Table I. (Continued)

\begin{tabular}{|c|c|c|c|c|c|c|}
\hline \multirow[t]{3}{*}{ Variable } & \multirow{3}{*}{$\begin{array}{l}\text { All patients } \\
(n=720)\end{array}$} & \multicolumn{4}{|c|}{$\begin{array}{l}\text { Subgroup by self-rated health (worst of two } \\
\text { observations) }\end{array}$} & \multirow[t]{3}{*}{$P$ value } \\
\hline & & \multirow{2}{*}{$\begin{array}{l}\text { Excellent or } \\
\text { very good } \\
(n=45)\end{array}$} & \multirow{2}{*}{$\begin{array}{l}\text { Good } \\
(n=308)\end{array}$} & \multirow{2}{*}{$\begin{array}{l}\text { Fair } \\
(n=277)\end{array}$} & \multirow{2}{*}{$\begin{array}{l}\text { Poor } \\
(n=90)\end{array}$} & \\
\hline & & & & & & \\
\hline Antidepressant, n (\%) & $22(3)$ & I (2) & $5(2)$ & $12(4)$ & $4(4)$ & 0.060 \\
\hline Anti-arrhythmics, n (\%) & $77(\mathrm{II})$ & $5(\mathrm{II})$ & $34(I I)$ & $26(9)$ & $12(13)$ & 0.976 \\
\hline \multicolumn{7}{|l|}{ Questionnaires } \\
\hline PHQ-9 sum score, mean \pm SD & $6.0 \pm 5.1$ & $3.0 \pm 3.4$ & $4.3 \pm 4.0$ & $6.9 \pm 4.7$ & $10.3 \pm 6.4$ & $<0.001$ \\
\hline SF36 psychosocial sum score, mean \pm SD & $48 \pm 11$ & $55 \pm 10$ & $51 \pm 10$ & $45 \pm 11$ & $39 \pm 13$ & $<0.001$ \\
\hline SF36 physical score, mean \pm SD & $40 \pm 9$ & $48 \pm 7$ & $43 \pm 8$ & $36 \pm 8$ & $33 \pm 8$ & $<0.001$ \\
\hline SF36 social functioning scale, mean $\pm S D$ & $7 I \pm 25$ & $88 \pm 18$ & $79 \pm 21$ & $66 \pm 23$ & $53 \pm 29$ & $<0.001$ \\
\hline
\end{tabular}

$P$ values are for ordinal trends (assessed by Kendall's correlation coefficient), that is, for the test whether increasing category of self-rated health is associated with increasing or decreasing values of the respective variables.

ACE: angiotensin-converting enzyme; ARB: angiotensin receptor blocker; eGFR: estimated glomerular filtration rate; $\mathrm{FEV}_{1}$ : forced one-second expiratory volume; high educational level: $\geqslant 12$ years of school or trade certificate; NTproBNP: N-terminal pro B-type natriuretic peptide; NYHA: New York Heart Association; PHQ: patient health questionnaire; SD: standard deviation; SF36: Medical Outcomes Study short form-36 questionnaire.

higher NYHA class, lower forced expiratory volume in 1 second $\left(\mathrm{FEV}_{1}\right)$, presence of oedema, lower haemoglobin levels and a history of diagnosed depression as well as higher self-reported depressive symptoms. Patients with fair/poor self-rated health were also more likely to be experiencing atrial fibrillation and chronic obstructive pulmonary disease, had higher NTproBNP levels and had more hospitalisations in the past year. High educational level, better performance on the 6-minute walk test, and better overall self-reported physical as well as psychosocial and social function were associated with better selfrated health. Patients with better self-rated health were more likely to experience coronary heart disease, had lower uric acid levels (no difference in estimated glomerular filtration rate between groups), and were more often on statins as well as antiplatelet therapy. There was no difference in self-rated health depending on whether patients had HFrEF versus HFpEF (Table 1).

\section{Self-rated health and survival}

Figure 2 shows the results of bivariate analyses, evaluating the prognostic value of self-rated health at both time points individually and in combination (best of two, worst of two). Worse self-rated health was associated with worse prognosis, independent of whether self-rated health assessment was made before or after beta-blocker titration. The worst of the two observations had the strongest ability to predict mortality (hazard ratio 1.42 per level worse, 95\% confidence interval 1.16-1.75, $P<0.001$ ). Changes in self-rated health between the two measurements were not predictive for mortality and the impact of self-rated health was the same in both CIBIS-ELD study arms (data not shown).
Kaplan-Meier curves (Figure 3) show that poor selfrated health predicts shorter survival than excellent/very good self-rated health $(P<0.001)$. When quantifying the relationship between self-rated health and the primary endpoint using Cox regression, poor self-rated health remained independently significant after adjusting for NTproBNP and other known risk predictors such as NYHA class and heart rate (hazard ratio $1.23, P=0.045$; Table 2). Although most of the predictor variables were correlated with each other, there was no relevant multicollinearity. One level worse self-rated health is as predictive for mortality as is each of the following: age by 3.2 years older, heart rate higher by 16 beats per minute, haemoglobin lower by $1.4 \mathrm{~g} / \mathrm{dL}$, or a 1.9 -fold increase in NTproBNP.

\section{Discussion}

This is the first study analysing the relationship between two consecutive self-rated health assessments and mortality in patients with heart failure. We found that poor self-rated health independently predicts mortality, even if this self-rating improves at a later date. Furthermore, this finding holds true for patients with $\mathrm{HFrEF}$ as well as those with $\mathrm{HFpEF}$.

When analysing the last of two observations, as well as the average, the worst and the best of both with mortality, we found that fair or poor self-rated health at any one time point predicted poor outcome. In other words, self-rated good health indicated good prognosis reliably only when stated at repeated measurements, but self-reported fair or poor health predicted poor prognosis when stated only once. Thus, our study also adds information to one of the central questions in self-rated health research: Is it poor self-rated health that predicts mortality or good self-rated health that predicts survival?27 The patient's perception of 


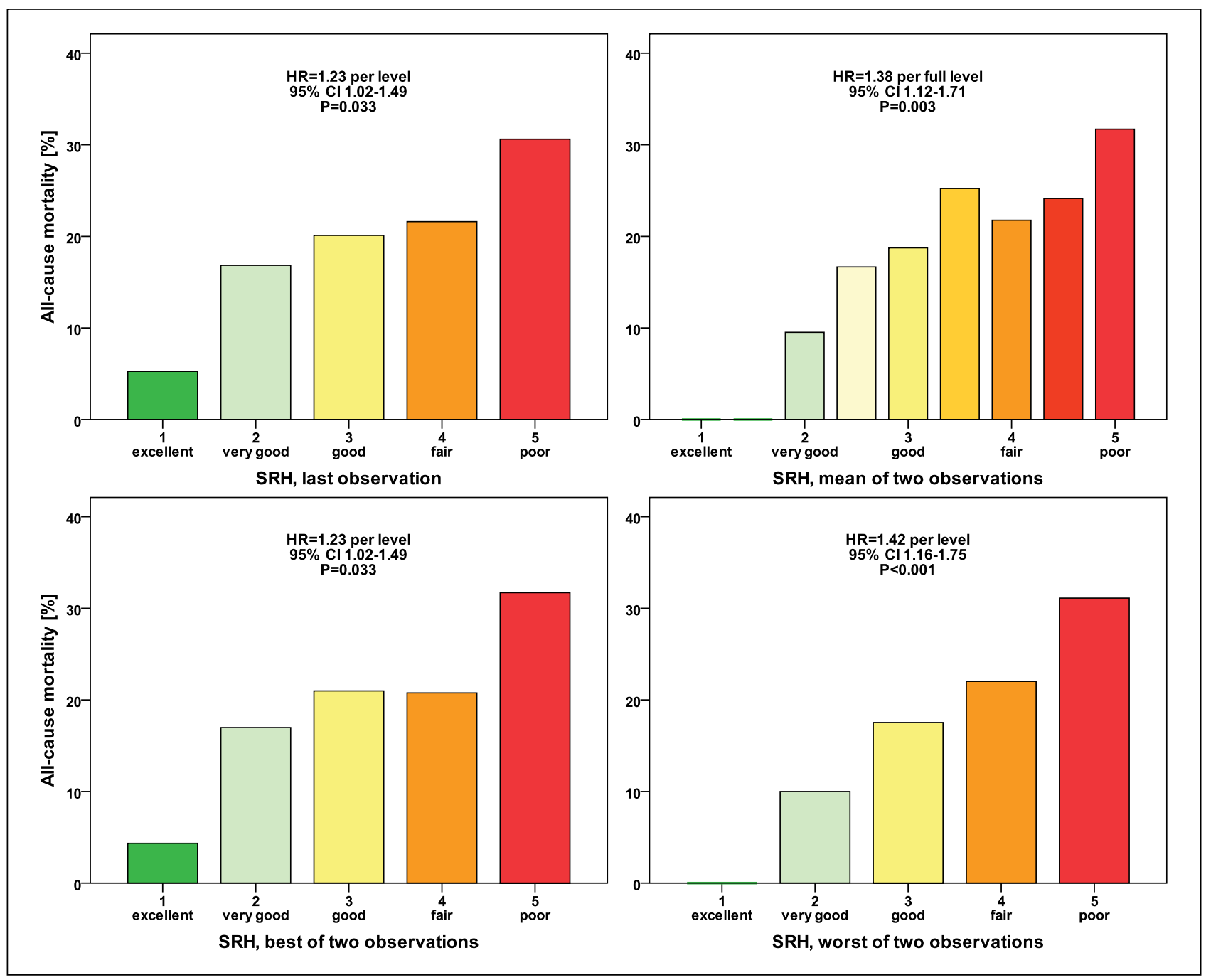

Figure 2. Mortality risk depending on self-rated health assessment.

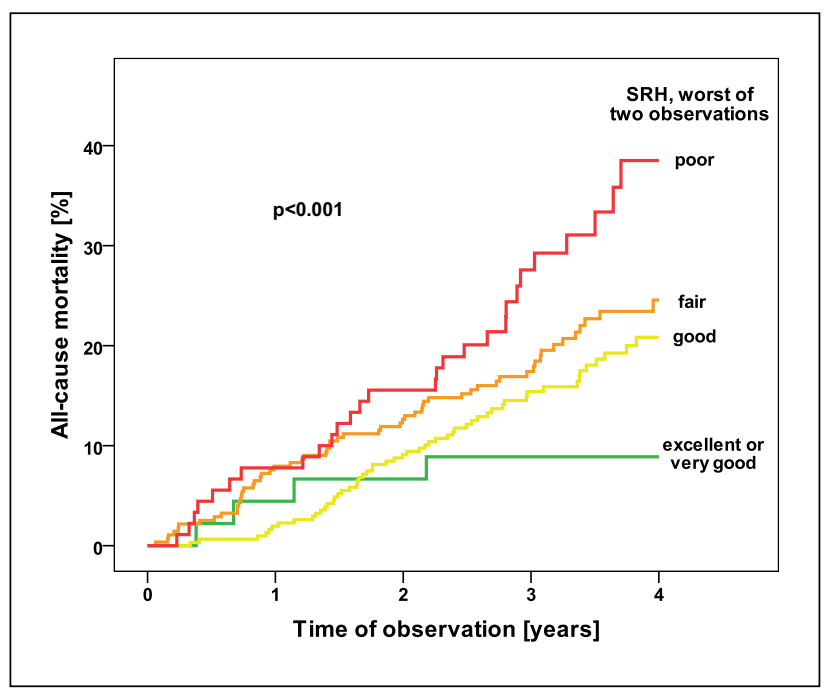

Figure 3. Kaplan-Meier curves for mortality. poor self-rated health at any one time might dominate the rest of the information. Results could also have practical implications: A one-off assessment of self-rated health is useful, but might not be sufficient for the prognostication of outcome above and beyond traditional risk variables in this population.

A one-point self-rated health assessment was predictive for mortality in our study, confirming the results of others. ${ }^{15-17}$ However, while the last observed value and the better of two observations were predictive in bivariate analysis, they became non-significant after adjustment for age. One explanation for this might be that our population consisted of older patients, reflecting a typical sample of chronic heart failure patients in the community ${ }^{1}$ with a mean age of 73 years, and it has previously been suggested that the predictive value of self-rated health lessens with advancing age. ${ }^{28-30}$

We included both NTproBNP and heart rate as known heart failure mortality risk predictors ${ }^{31-34}$ in our multiple 
Table 2. Multiple Cox regression for all-cause mortality.

\begin{tabular}{|c|c|c|}
\hline Variable & Hazard ratio $(95 \% \mathrm{Cl})$ & $P$ value \\
\hline $\begin{array}{l}\text { Self-rated health, worst of } \\
\text { two observations (per level) }\end{array}$ & $1.23(1.00-1.52)$ & 0.045 \\
\hline Age (per decade older) & $1.91(1.39-2.64)$ & $<0.001$ \\
\hline Women vs. men & $0.63(0.41-0.96)$ & 0.033 \\
\hline NYHA class (per class higher) & $0.99(0.73-1.34)$ & 0.950 \\
\hline $\begin{array}{l}\text { Left ventricular function } \\
\text { (systolic vs. diastolic heart } \\
\text { failure) }\end{array}$ & $1.47(0.92-2.37)$ & 0.111 \\
\hline $\begin{array}{l}\text { Hospitalisation for heart } \\
\text { failure in the past year }\end{array}$ & $1.29(0.91-1.83)$ & 0.146 \\
\hline $\begin{array}{l}\text { Six-minute walk distance } \\
\text { (per } 100 \mathrm{~m} \text { more) }\end{array}$ & $0.81(0.68-0.96)$ & 0.016 \\
\hline $\begin{array}{l}\text { Heart rate (per } 10 \text { bpm } \\
\text { higher) }\end{array}$ & $1.14(1.01-1.29)$ & 0.037 \\
\hline Haemoglobin (per g/dl higher) & $0.86(0.77-0.95)$ & 0.005 \\
\hline Uric acid (per mg/dl higher) & $1.04(0.95-1.13)$ & 0.443 \\
\hline $\begin{array}{l}\text { eGFR (per } 10 \mathrm{ml} / \mathrm{min} / 1.73 \mathrm{~m}^{2} \\
\text { higher) }\end{array}$ & $0.99(0.90-1.10)$ & 0.874 \\
\hline $\begin{array}{l}\text { NTproBNP } \\
\text { (per I0-fold increase) }\end{array}$ & $2.10(1.46-3.03)$ & $<0.001$ \\
\hline
\end{tabular}

eGFR: estimated glomerular filtration rate; NTproBNP: N-terminal pro B-type natriuretic peptide; NYHA: New York Heart Association.

regressions, and poor self-rated health withstood their scrutiny in detecting mortality risk independently. This is in line with previous studies ${ }^{15,17}$ and adds strength to the argument that self-rated health contains valuable information that cannot be gained through clinical or laboratory measurements.

Not surprisingly, we found that symptom burden, most notably expressed in higher NYHA class, lower $\mathrm{FEV}_{1}$, and lower 6-minute walk test distance, as well as a greater amount of hospitalisations in the past year, lower perceived quality of life and depressive symptoms are associated with worse self-rated health. These findings confirm results from a cross-sectional study on predictors of self-rated health in heart failure. ${ }^{5}$ Self-reported health measurements reflect not only the physical aspects of disease but the illness impact on lifestyle, social functioning and expectations of the patient. ${ }^{35}$ Despite recent advances in pharmacological therapy, heart failure has enormous implications on everyday life and functioning, as well as on psychosocial well-being. Most patients with heart failure experience multiple other chronic illnesses and their selfrated health is likely to be influenced by the sum of their illnesses.

Overall, women reported worse self-rated health than men, and we included this factor in our multivariate model. The gender difference in self-rated health assessment has been well documented. ${ }^{4,8,27}$ Most studies come to the conclusion that in women, the self-rated health-mortality association is less pronounced and further decreases with the length of follow-up. ${ }^{36}$ One of the possible explanations for this is that men have a shorter life expectancy than women, who are more likely to live with health problems for longer periods of time, which in turn has an effect on self-ratings of health. ${ }^{36}$ In addition, the process of individual health evaluation is influenced by physical as well as psychological factors and is embedded in social environments, ${ }^{30}$ which differ between genders.

We extended previous work by demonstrating the value of self-rated health measurement in heart failure irrespective of ejection fraction. There was no difference in selfrated health and its association with mortality depending on the type of heart failure (HFrEF vs. HFpEF). This is important as current mortality rates in patients with $\mathrm{HFrEF}$ and HFpEF are comparable. ${ }^{1}$ However, given the lack of established pharmacological treatments to reduce mortality in HFpEF, the prevalence of HFpEF is rising. ${ }^{37}$ Thus, any further identification of variables that provide important prognostic information in this population may enhance our ability to improve care.

Alongside clinical parameters, the patient's perception of their health is what should co-determine our treatment approach. The World Health Organization has recommended self-rated health as a measure of health status for almost 20 years..$^{38}$ We support the recent call for creating a holistic approach to clinical decision making, ${ }^{3}$ and recommend that clinicians routinely and repeatedly include selfrated health in their interactions with patients. Many clinicians will argue that their approach to clinical decision making is holistic in that it includes patient wishes, preferences and perception, and rightly so. Our argument for assessing self-rated health in a standardised form is that this might reduce the risk of misinterpretation of clues and messages given by a patient during a consultation. In a cross-sectional study analysing differences in self-rated versus clinician-rated standardised global health, we found that, overall, patients with heart failure self-rate their health as worse than the clinician. ${ }^{39}$ Translating this into clinical practice and taking the results of the current study into account, a clinician might underestimate a patient's risk for adverse outcome by overestimating their health. The standardised self-rated health assessment may add value by validating and clarifying the patient's perception in a structured way. In a second step, clinicians can then explore with the patient why they are feeling that way and specifically address the issues identified.

Opportunities for future research exist in the exploration of structured interviews when self-rated health is poor, and what follow-up should be undertaken in this case. From another perspective, good self-rated health was associated with higher scores on the physical, psychological and social functioning scales of the SF-36 in our study. This information may provide us with cues on designing future research on how to improve self-rated health. The authors of the to-date longest studied general population cohort with regard to self-rated health conclude that their 
results, which confirm mortality prediction even after 30 years, support a salutogenic rather than pathogenic pathway underlying the persistent and independent self-rated health-mortality association. ${ }^{4}$ On that basis, future studies could test the potential benefit of different interventions that utilise the person's existing resources and strengths in domains that are associated with good self-rated health.

\section{Limitations}

While being a typical situation in routine clinical practice, the up-titration of beta-blockers in our sample was part of a clinical trial. It is possible that the mere participation in our study influenced self-rated health. The mortality rate after 4 years in our study was $20 \%$, which is less than previously reported. ${ }^{1,16}$ One of the main differences between the aforementioned studies and ours is that patients were on maximally tolerated, optimal pharmaceutical therapy.

We only captured all-cause mortality in our observational follow-up and are therefore unable to report details with regard to cause-specific mortality or hospitalisations.

Self-rated health is considered part of quality of life, an essential factor to consider in the treatment of heart failure. Our study did not attempt to address the superiority of selfrated health to assessment of quality of life.

\section{Conclusions and clinical implications}

The simple question of 'How do you rate your health in general?' predicts mortality in our analysis of well characterised patients with heart failure, even after adjustment for established risk prediction covariates. Consecutive assessment of self-rated health has greater predictive value than a one-point measurement only. Including this simple tool in our clinical assessment to evaluate a patient's perspective in a standardised form may support us in our holistic approach to improving heart failure care.

\section{Implications for practice}

- We encourage nursing and medical clinicians to routinely capture standardised self-rated health by asking "In general, would you say your health is: excellent, very good, good, fair, poor".

- Patients rating their health as only fair or poor may be at greater risk for mortality, independent of objective clinical measurements. Clinicians may wish to consider closer follow-up in this case.

- We encourage clinicians to explore with the patient the reasons for why they rate their health as fair or poor. This may provide them with further cues for individualised care.

\section{Acknowledgements}

The authors would like to thank the study participants for their time and commitment.

\section{Conflict of Interest}

None declared.

\section{Funding}

This work was supported by the Competence Network Heart Failure, funded by the Federal Ministry of Education and Research (BMBF), FKZ 01GI0205. The sponsor of the CIBISELD trial according to ICH-GCP was the ChariteUniversitätsmedizin Berlin, Germany.

\section{References}

1. McMurray JJ, Adamopoulos S, Anker SD, et al.; Task Force for the Diagnosis and Treatment of Acute and Chronic Heart Failure 2012 of the European Society of Cardiology, Bax JJ, Baumgartner H, Ceconi C, et al.; ESC Committee for Practice Guidelines. Eur J Heart Fail 2012; 14: 803-869.

2. Fonarow GC. Clinical risk prediction tools in patients hospitalized with heart failure. Rev Cardiovasc Med 2012; 13: e14-23.

3. Anker SD, Agewall S, Borggrefe M, et al. The importance of patient-reported outcomes: a call for their comprehensive integration in cardiovascular clinical trials. Eur Heart $J$ 2014; 35: 2001-2009.

4. Bopp M, Braun J, Gutzwiller F, et al.; for the Swiss National Cohort Study Group. Health risk or resource? Gradual and independent association between self-rated health and mortality persist over 30 years. PLoS ONE 2012; 7: e30795.

5. Carlson B, Pozehl B, Hertzog M, et al. Predictors of overall perceived health in patients with heart failure. $J$ Cardiovasc Nurs 2013; 28: 206-215.

6. Hayes AJ, Clarke PM, Glasziou PG, et al. Can self-rated health scores be used for risk prediction in patients with type 2 diabetes? Diabetes Care 2008; 31: 795-797.

7. Benyamini Y, Gerber N, Molshatzki N, et al.; Israel Study Group on First Acute Myocardial Infarction. Recovery of self-rated health as a predictor of recurrent ischemic events after first myocardial infarction: A 13-year follow-up. Health Psychol 2013; 33: 317-325.

8. Idler EL and Benyamini Y. Self-rated health and mortality: A review of twenty-seven community studies. J Health Soc Behav 1997; 38: 21-37.

9. Farkas J, Kosnik M, Flezar M, et al. Self-rated health predicts acute exacerbations and hospitalisations in patients with COPD. Chest 2010; 138: 323-330.

10. Thong MS, Kaptein AA, Benyamini Y, et al.; Netherlands Cooperative Study on the Adequacy of Dialysis (NECOSAD) Study Group. Association between a self-rated health question and mortality in young and old dialysis patients: a cohort study. Am J Kidney Dis 2008; 52: 111-117.

11. Mäntyselkä PT, Turunen JH, Ahonen RS, et al. Chronic pain and poor self-rated health. JAMA 2003; 290: 2435-2442.

12. Lainscak M, Farkas J, Inkrot S, et al. Self-rated health predicts adverse events during beta-blocker treatment: the CIBIS-ELD randomised trial analysis. Int J Cardiol 2013; 163: 87-92. 
13. Havranek EP, Lapuerta P, Simon TA, et al. A health perception score predicts cardiac events in patients with heart failure: results from the IMPRESS trial. J Card Fail 2001; 7: 153-157.

14. Konstam V, Salem D, Pouleur H, et al. Baseline quality of life as a predictor of mortality and hospitalization in 5,025 patients with congestive heart failure. SOLVD Investigations. Studies of Left Ventricular Dysfunction Investigators. Am J Cardiol 1996; 78(8): 890-895.

15. Johansson P, Broström A, Dahlström U, et al. Global perceived health and ten-year cardiovascular mortality in elderly primary care patients with possible heart failure. Eur J Heart Fail 2008; 10: 1040-1047.

16. Farkas J, Nabb S, Zaletel-Kragelj L, et al. Self-rated health and mortality in patients with chronic heart failure. Eur $J$ Heart Fail 2009; 11: 518-524.

17. Hoekstra T, Jaarsma T, van Veldhuisen DJ, et al. Quality of life and survival in patients with heart failure. Eur J Heart Fail 2013; 15: 94-102.

18. Mastenbroek MH, Versteeg H, Zijlstra W, et al. Diseasespecific health status as a predictor of mortality in patients with heart failure: a systematic literature review and metaanalysis of prospective cohort studies. Eur J Heart Fail 2014; 16: 384-393.

19. Düngen $\mathrm{HD}$, Apostolovic $\mathrm{S}$, Inkrot $\mathrm{S}$, et al.; CIBISELD Investigators, Subproject Multicenter Trials in the Competence Network Heart Failure. Bisoprolol vs. carvedilol in elderly patients with heart failure: rationale and design of the CIBIS-ELD trial. Clin Res Cardiol 2008; 97: 578-586.

20. Düngen HD, Apostolovic S, Inkrot $\mathrm{S}$, et al.; CIBIS-ELD investigators and Project Multicentre Trials in the Competence Network Heart Failure. Titration to target dose of bisoprolol vs. carvedilol in elderly patients with heart failure: the CIBISELD trial. Eur J Heart Fail 2011; 13: 670-680.

21. WHO. Physical Status: The Use and Interpretation of Anthropometry. Report of a WHO Expert Committee. Geneva: World Health Organization 1995; 854: 1-452.

22. WHO. Haemoglobin Concentrations for the Diagnosis of Anaemia and Assessment of Severity. Vitamin and Mineral Nutrition Information System. Geneva, World Health Organization, 2011 (WHO/NMH/NHD/MNM/11.1) (http:// www.who.int/vmnis/indicators/haemoglobin.pdf, accessed 02.09.2015).

23. ATS Committee on Proficiency Standards for Clinical Pulmonary Function Laboratories. ATS statement: guidelines for the six-minute walk test. Am J Respir Crit Care Med 2002; 166: 111-117.

24. Ware JE Jr and Sherbourne CD. The MOS 36-item shortform health survey (SF-36). I. Conceptual framework and item selection. Med Care 1992; 30: 473-483.

25. Kroenke K, Spitzer RL and Williams JB. The PHQ-9: validity of a brief depression severity measure. J Gen Intern Med 2001; 16: 606-613.
26. DeSalvo KB, Fisher WP, Tran K, et al. Assessing measurement properties of two single-item general health measures. Qual Life Res 2006; 15: 191-201.

27. Benyamini Y, Blumstein T, Lusky A, et al. Gender differences in the self-rated health-mortality association: is it poor self-rated health that predicts mortality or excellent selfrated health that predicts survival? Gerontologist 2003; 43: 396-405.

28. Heller DA, Ahern FM, Pringle KE, et al. Among older adults, the responsiveness of self-rated health to changes in Charlson comorbidity was moderated by age and baseline comorbidity. J Clin Epidemiol 2009; 62: 177-187.

29. French DJ, Sargent-Cox K and Luszcz MA. Correlates of subjective health across the aging lifespan: understanding self-rated health in the oldest old. J Aging Health 2012; 24(8): 1449-1469.

30. Jylhä M. What is self-rated health and why does it predict mortality? Towards a unified conceptual model. Soc Sci Med 2009; 69(3): 307-316.

31. Lainscak M, von Haehling S and Anker SD. Natriuretic peptides and other biomarkers in chronic heart failure: From BNP, NT-proBNP, and MR-proANP to routine biochemical markers. Int J Cardiol 2009; 132: 303-311.

32. McAlister FA, Wiebe N, Ezekowitz JA, et al. Metaanalysis: beta-blocker dose, heart rate reduction, and death in patients with heart failure. Ann Intern Med 2009; 150: 784-794.

33. Gelbrich G, Edelmann F, Inkrot S, et al.; CIBIS-ELD investigators. Is target dose the treatment target? Uptitrating betablockers for heart failure in the elderly. Int J Cardiol 2012; 155: 160-166.

34. Düngen HD, Musial-Bright L, Inkrot S, et al. Heart rate following short-term beta-blocker titration predicts all-cause mortality in elderly chronic heart failure patients: insights from the CIBIS-ELD trial. Eur J Heart Fail 2014; 16: 907914.

35. Ekman I, Cleland JG, Andersson B, et al. Exploring symptoms in chronic heart failure. Eur $J$ Heart Fail 2005; 7: 699-703.

36. Deeg DJ and Kriegsman DM. Concepts of self-rated health: specifying the gender difference in mortality risk. Gerontologist 2003; 43(3): 376-386.

37. Owan TE, Hodge DO, Herges RM, et al. Trends in prevalence and outcome of heart failure with preserved ejection fraction. N Engl J Med 2006; 355(3): 251-259.

38. de Bruin A, Picavet HSJ and Nossikov A (eds). Health Interview Surveys: Towards International Harmonization of Methods and Instruments. Copenhagen, Denmark: WHO Regional Office for Europe, 1996. (WHO regional publications, European series, no. 58).

39. Inkrot S, Tahirovic E, Lainscak M, et al. Comparison of patients self-rated versus physician-rated global health in heart failure. Eur J Cardiovasc Nurs 2013; 12: S67. 